\title{
Profile of Ovarian Cancer Patients In Mangusada Badung Regional Public Hospital
}

\author{
Bagus Ngurah Brahmantara ${ }^{1}$, AA Ngurah Agung Putra Wirawan ${ }^{1}$, I Gusti Ngurah \\ Agung Trisnu Kamajaya ${ }^{2^{*}}$ \\ ${ }^{1}$ Department of Obstetric and Gynecology, Mangusada Badung Regional Public Hospital, Bali, Indonesia \\ ${ }^{2}$ Mangusada Badung Regional Public Hospital, Bali, Indonesia
}

\section{ARTICLE INFO}

Received : 27 August 2020

Reviewed : 14 September 2020

Accepted : 22 June 2021

Keywords:

ovarian cancer, profile

\author{
*Corresponding author: \\ I Gusti Ngurah Agung Trisnu \\ Kamajaya \\ Medical Doctor at Mangusada \\ Badung Regional Public Hospital, Bali, \\ Indonesia \\ Trisnukamajaya@aol.com
}

\begin{abstract}
A BSTRACT
Background: Ovarian cancer is still one of the neoplasms within the gynecology scope. Besides, World Health Organization (WHO) states that ovarian cancer ranks fourth cancer in women with the lowest five-year survival rate (43\%). Thus, this research aims to recognize the risk factors in patients with ovarian cancer and the commonly found characteristic.
\end{abstract}

\begin{abstract}
Methods: This cross-sectional observational research on 29 women diagnosed with ovarian cancer observed the age, parity, body mass index (BMI), contraception, character, and stadium. The medical record samples based on patients' registers were obtained from the Obstetrics and Gynecologic Polyclinic in Mangusada Badung Regional Public Hospital in the January-December 2019 period, and the result data were distributed using contingency tables.
\end{abstract}

Results: The data dominantly diagnosed ovarian cancer, with age distribution 51-60 years (34.5\%), $44.8 \%$ with obesity, $44.8 \%$ nullipara, without a history of contraceptive use, menarche within 12 years old $(41.4 \%)$, diagnosed stage IIIC (42.3\%), and with serous epithelial tumor subclassification (65.5\%).

Conclusions: Predominant ovarian cancer is found at a late stage. The most common risk factors of developing ovarian cancer, including the age of 51-60, obesity, menarche within 12 years old, and no history of hormonal contraceptive use, are consistent with this research hypothesis about risk factors dominantly found in patients with ovarian cancer..

\section{INTRODUCTION}

Ovarian cancer or ovarian carcinoma is one of the neoplasms on the female genitalia, which has been the leading problem in gynecology scope, caused by the high mortality rate reaching almost half of the overall mortality rate due to gynecologic malignancies [1]. The World Health Organization (WHO) also states that ovarian cancer is the fourth rank of cancer among women worldwide and contributes to the high mortality rate. In the United States, research revealed that about $54 \%$ of women diagnosed with ovarian cancer died from it. Furthermore, according to data from the Center for Disease Control and Prevention, ovarian cancer is gynecological cancer with the lowest five-year survival rate worldwide, at around $43 \%$ [2].

The high case fatality rate is contributed by the many biases and unspecific characteristics commonly seen at the end-stage because of the spread of this tumor and enlargement in other organs with mostly no complaints [3]. Ovarian cancer will often cause complaints after spreading to the peritoneum or even detected on followup examinations after spreading the other organs. This condition primarily causes no effect on surgical therapy nor adjuvant therapy [4]. Although early detection or examination as a prevention modality commonly used only in high-risk patients does not seem practical or capable of lowering mortality when used for other risk factors, it is necessary to find the earliest stadium of ovarian cancer to increase a patient's life expectancy [1]. In this case, profile and risk characteristics seen as predisposing to ovarian cancer need to be reevaluated to manage ovarian cancer effectively.

Therefore, a risk factor assessment is needed to see its relation as a predictor of examination and early detection. Several risk factors seem to play a role in 
the development of ovarian cancer, such as having inherited ovarian cancer, colon and breast cancer, gene mutation, age over 50 years, nullipara, gestational age over 35 years, history of hormonal contraceptive use, and obesity [1,3]. In addition, any delay and difficulty in diagnosing ovarian cancer are also related to the totipotent character of the ovarium, concealed location of ovarium within the pelvic cavity, susceptibility to metastases, unspecific symptoms, a remote social culture, and education.

As one of the referral centers, Mangusada Badung Regional Public Hospital has experts in treating cases related to oncology and gynecology scopes but still does not have profile data and histopathological descriptions of ovarian cancer representing the Badung area. For this reason, it seems necessary because the profile of patients with ovarian cancer from each site may differ due to different factors related to social and cultural aspects. Thus, factual data are needed to represent the ovarian cancer profile at the Mangusada Badung Regional Public Hospital in January-December 2019.

\section{METHODS}

This research used a descriptive study method with a cross-sectional approach. The data were collected from the patients' medical records diagnosed with ovarian cancer in their histological results, confirmed after complete surgery at Mangusada Badung Regional Public Hospital from January to December 2019. This research employed a total sampling to fulfill the significant base sample from the patients' medical records diagnosed and traced with ovarian cancer in the Obstetric and Gynecologic Clinic at Mangusada Badung Regional Public Hospital in 2019. The data from the medical records included age, menarche age, parity, weight/height, tumor classification, and stadium of malignancy based on FIGO classification. The data were then analyzed utilizing SPSS 16.0 for windows software and converted into tables and narratives. In addition, the statistical analysis used in this research was univariate analysis to interpret each variable.

\section{RESULTS}

This research's results were obtained after analyzing 29 samples of patients diagnosed with ovarium malignancy from the Obstetrics and Gynecology Polyclinic register in Mangusada Badung Regional Public Hospital in January-December 2019 by matching the register data and medical record numbers stored in the hospital. It aimed to know the characteristic profile of patients with ovarian cancer at Mangusada Badung Regional Public Hospital. Table 1 explains that more than 60\% of patients were diagnosed in the end-stage (stadium III malignancy).
This research found about $65.5 \%$ of patients with serous tumor subclassification, with the lowest percentage being mixed germ cell tumors. This study predominantly uncovered that ovarian cancer was diagnosed at the age of 51-60 years, but then decreased in the age group of 60 years, and fewer patients were diagnosed with ovarian cancer in the age group less than 30 .

The most highly diagnosed ovarian cancer was in patients with obesity (BMI $>25 \mathrm{~kg} / \mathrm{m} 2)$. The percentage increases in line with the increase in the BMI of the age group. In addition, nullipara was found dominantly in patients with ovarian cancer than primipara and multipara. This research also reviewed the overall contraceptive use in patients with ovarian cancer. Table $\mathbf{1}$ displays that almost half of the patients with ovarian cancer admitted to having early menarche at the age of 12 years, while the percentage at the later age of menarche was minor.

Figure 1 reveals that patients with IB were dominantly subclassified as mucinous and serous tumors. Meanwhile, patients with IC stadium diagnoses were predominantly subclassified as serous and endometrioid. Hence, one patient was with a serous, mucinous, yet mixed germ cell tumor, diagnosed with IIB stadium. Stadium IIIA and IIIB were found only with a serous subclassification, whereas stadium IIIC was dominated with serous subclassification followed by endometrioid subclassification. Meanwhile, serous subclassification was found in all stadiums of patients with ovarian cancer. As described in Figure 2, serous subclassification was found in all age groups and was the most dominant tumor subclassification group in ovarian cancer.

As shown by Table 2, the earlier stage was commonly seen at an earlier age, and the later stages were seen in the older age groups.

\section{DISCUSSION}

Ovarian cancer or ovarian carcinoma is one of the neoplasms on the female genitalia, which has been the leading problem in gynecology scope, caused by the high mortality rate reaching almost half of the overall mortality rate due to gynecologic malignancies [1]. The high case fatality rate is contributed by the many biases and unspecific characteristics commonly seen at the end-stage because of the spread of this tumor and enlargement in other organs with mostly no complaints [2]. Therefore, the profile and risk characteristics of predisposing to ovarian cancer need to be reevaluated to manage ovarian cancer effectively and efficiently. Furthermore, age was said to affect significantly, namely at ages older than 65 years. Although the relationship between age and the prevalence of ovarian cancer has not yet been elucidated, several studies have explained 


\section{Table 1.}

Frequency distribution of ovarian cancer based on the clinical variables.

\begin{tabular}{|c|c|c|}
\hline Characteristics & $\mathbf{N}$ & Percentage (\%) \\
\hline \multicolumn{3}{|l|}{ Stadium } \\
\hline IB & 5 & $17.2 \%$ \\
\hline IC & 3 & $10.3 \%$ \\
\hline IIB & 3 & $10.3 \%$ \\
\hline IIIA & 2 & $6.9 \%$ \\
\hline IIIB & 2 & $6.9 \%$ \\
\hline IIIC & 14 & $48.3 \%$ \\
\hline \multicolumn{3}{|l|}{ Tumor subclassification } \\
\hline Serous & 19 & $65.5 \%$ \\
\hline Mucinous & 4 & $13.8 \%$ \\
\hline Endometrioid & 3 & $10.3 \%$ \\
\hline Clear cell & 2 & $6.9 \%$ \\
\hline Mixed germ cell tumor & 1 & $3.4 \%$ \\
\hline \multicolumn{3}{|l|}{ Body mass index (BMI) } \\
\hline$<18.5$ & 2 & $6.9 \%$ \\
\hline $18.5-22.9$ & 4 & $13.8 \%$ \\
\hline $22.9-25$ & 11 & $37.9 \%$ \\
\hline$>25$ & 12 & $41.4 \%$ \\
\hline \multicolumn{3}{|l|}{ Parity } \\
\hline$>2$ & 3 & $10.3 \%$ \\
\hline 2 & 10 & $34.5 \%$ \\
\hline 1 & 3 & $10.3 \%$ \\
\hline 0 & 13 & $44.8 \%$ \\
\hline \multicolumn{3}{|l|}{ Age of Menarche } \\
\hline 11 & 9 & $31.0 \%$ \\
\hline 12 & 12 & $41.4 \%$ \\
\hline 13 & 5 & $17.2 \%$ \\
\hline$>13$ & 3 & $10.3 \%$ \\
\hline
\end{tabular}

Table 2.

Cross-tabulation of stadium and group of age

\begin{tabular}{llllllll}
\hline \multirow{2}{*}{ Group of Age } & \multicolumn{2}{l}{$\begin{array}{l}\text { Stadium } \\
\text { Number (Percentage) }\end{array}$} & & & & Total \\
& IB & IC & IIB & IIIA & IIIB & IIIC & \\
\hline$<31$ & $3(10.3)$ & $0(0)$ & $2(6.9)$ & $0(0)$ & $0(0)$ & $0(0)$ & $5(17.2)$ \\
$31-40$ & $0(0)$ & $0(0)$ & $1(3.4)$ & $0(0)$ & $0(0)$ & $2(6.9)$ & $3(10.3)$ \\
$41-50$ & $0(0)$ & $1(3.4)$ & $0(0)$ & $1(3.4)$ & $1(3.4)$ & $2(6.9)$ & $5(17.2)$ \\
$51-60$ & $1(3.4)$ & $2(6.9)$ & $0(0)$ & $1(3.4)$ & $0(0)$ & $6(20.7)$ & $10(34.5)$ \\
$>60$ & $1(3.4)$ & $0(0)$ & $0(0)$ & $0(0)$ & $1(3.4)$ & $4(13.8)$ & $5(17.2)$ \\
Total & $5(17.2)$ & $3(10.3)$ & $3(10.3)$ & $2(6.9)$ & $2(6.9)$ & $14(48.3)$ & $29(100)$ \\
\hline
\end{tabular}




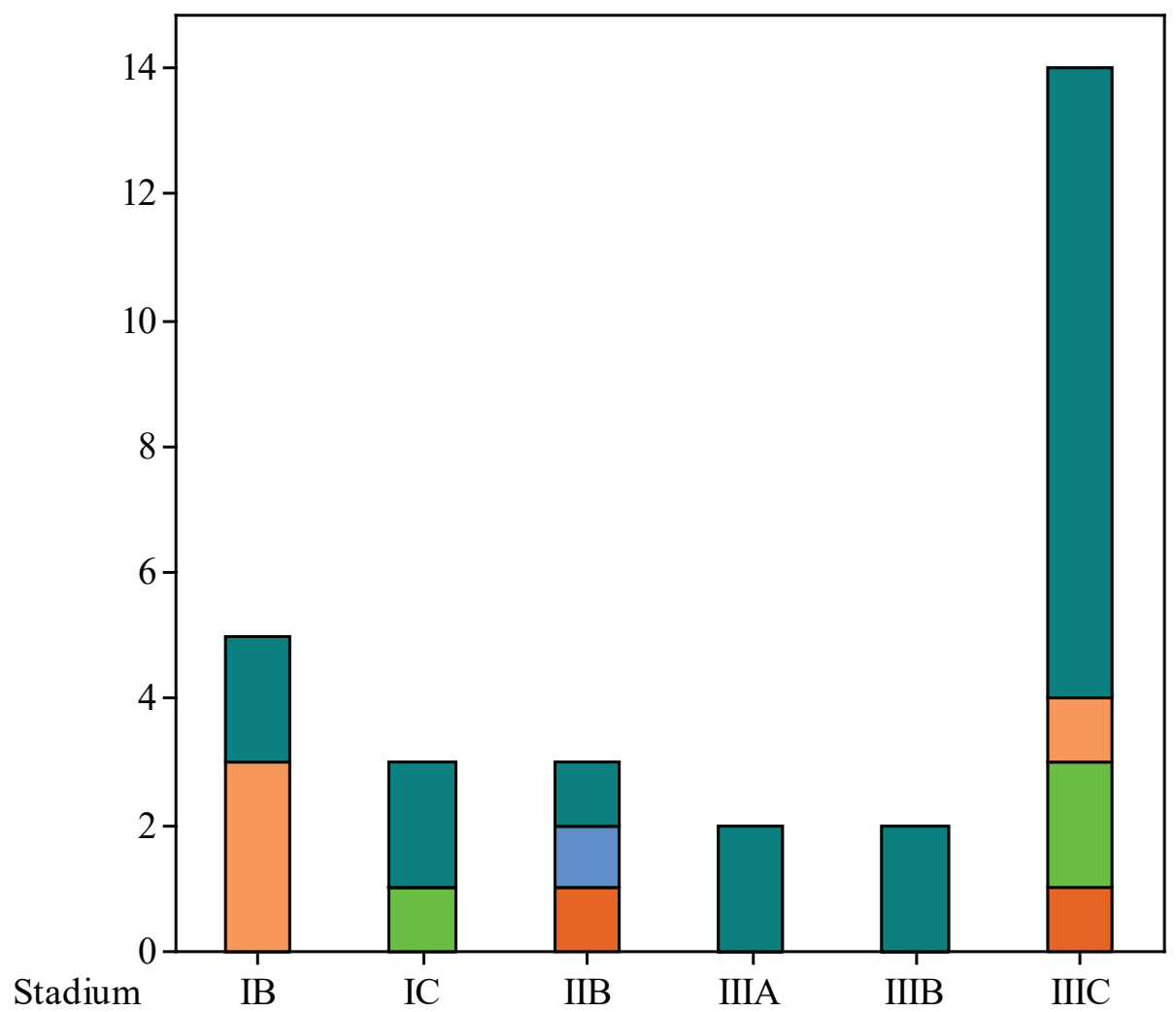

\begin{tabular}{|l|}
\hline$\square$ Serous \\
$\square$ Mucinous \\
$\square$ Mixed Germ Cell Tumor \\
$\square$ Endometrioid \\
$\square$ Clear Cell \\
\hline
\end{tabular}

Figure 1. Ovarian cancer distribution based on stadium and tumor subclassification

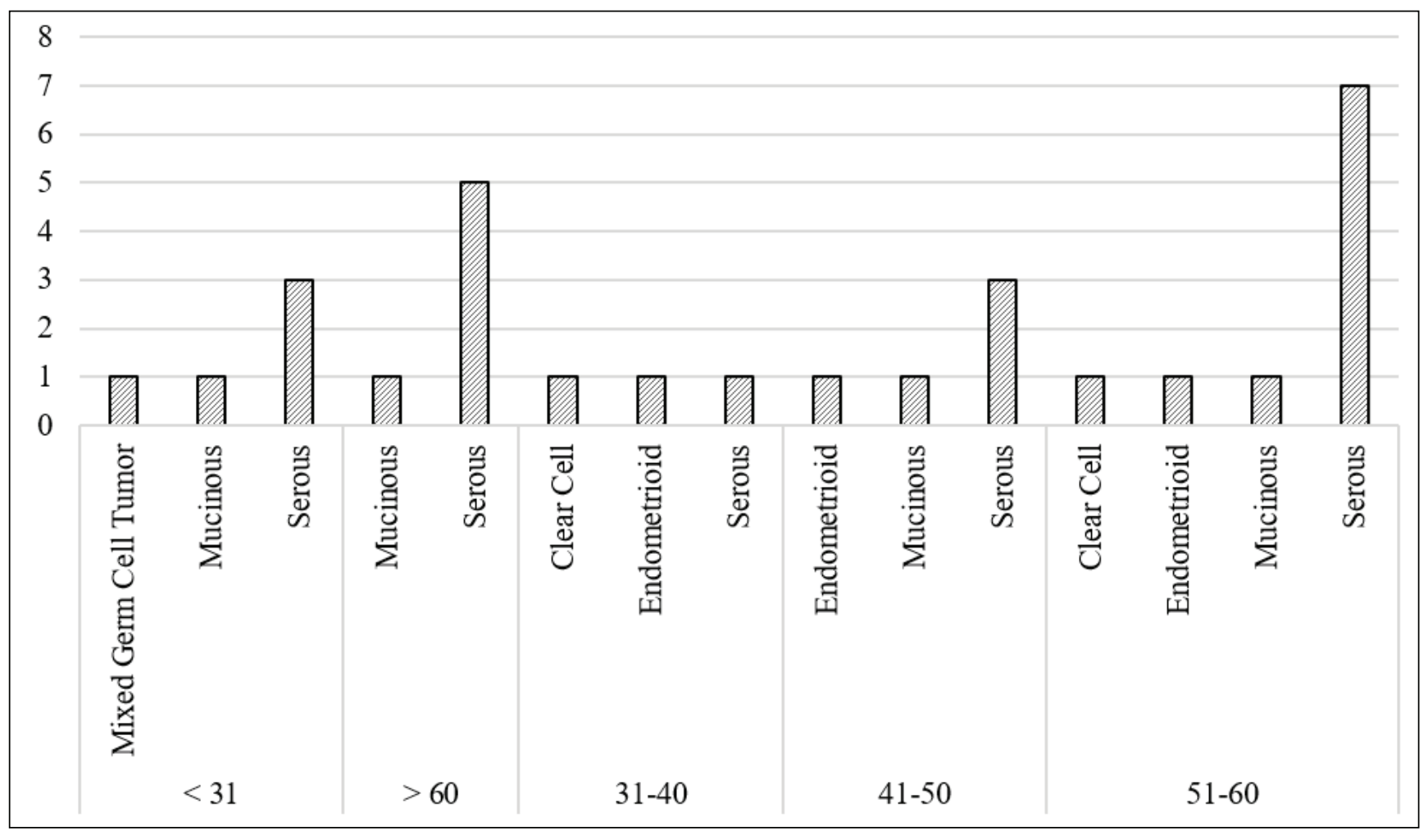

Figure 2. Ovarian cancer distribution based on the group of age and tumor subclassification 
that ovarian cancer is related to better outcomes at a younger age [3].

Based on this research, the distribution of ovarian cancer by age group showed that the oldest age found was 86 , and the youngest was 18 years. The most dominant ovarian cancer was around $34.5 \%$ at the age of $51-60$ years, followed by 60 years, but the lowest percentage of $10.3 \%$ was found at the age of $31-40$ years. It is in accordance with Prawiroharjo [4], who mentioned that ovarian cancer could come across all age groups from 20 to 80 years old. This research is directly proportional to the research conducted by Yanti \& Sulistianingsih [5] from Abdoel Moelok Hospital Lampung that ovarian cancer was found with the highest percentage of $82.4 \%$ at the age above 40 years. In addition, ovarian cancer is known as age-related cancer and is commonly a postmenopausal disease; the median age of ovarian cancer diagnosis is $50-79$ years, according to several observational studies conducted by Momenimovahed et al. [3]. Some literature has shown that ovarian cancer rates increase exponentially after 40 and $50-60$ years as the peak. It is related to several risk factors, such as histopathological subtypes that are most commonly found in ovarian carcinoma, the inheritance of ovarian cancer in the family, a long reproductive period, the first pregnancy after the age of 30 years, and several other things causing variations in the age of suffering from ovarian cancer [6].

The histological character of ovarian cancer has several types. WHO classifies ovarian cancer based on the histogenic type and classification by its origin: surface coelomic epithelial cells, germ cells, and mesenchymal cells (stromal and sex cord) [2]. Based on research conducted on 29 cases, 28 cases were found as surface epithelial cell subtypes and one case from germ cell subtypes. As a result, $65.5 \%$ were found to be subclassified as serous tumors, followed by $13.8 \%$ from mucinous, $10.3 \%$ from endometrioid type, and $6.9 \%$ from clear cell type. Meanwhile, the subclassification with the lowest percentage was occupied by mixed germ cell tumors, which was $3.4 \%$. Thus, it is related to the basic theory that ovarian epithelial tumors are the majority of ovarian malignancies, classified based on their histological types: serous, mucinous, endometrioid, clear cell, transitional cell tumor (Brenner tumors), and others [7].

This research supports the review from the American Cancer Society, which revealed serous carcinoma (52\%) to be dominant, clear cell carcinoma (6\%), mucinous carcinoma (6\%), and endometrioid carcinoma (10\%) [8]. Several ovarian cancer subtypes were evaluated and based on a review by Momenimovahed et al. [3], 90\% of ovarian cancer cases were based on epithelial cells, and the rest were non-epithelial cells. Epithelial subclassification was $3 \%$ from mucinous, and the rest were from non-mucinous, predominantly based on serous cells (70\% non-mucinous), endometrioid (10\%), clear cells $(10 \%)$, and unspecific type (5\%). In Bali, research by Dhitayoni \& Budiana [6] and Budiana et al. [7] also stated that the dominant percentage of $87.7 \%$ of histopathological types of ovarian cancer was a surface epithelial type, and from this percentage, the most common subtype was serous epithelial subtype.

Cross-data tabulation was used to understand the histopathological distribution by age. In this research, patients with age groups less than 31 years and 41-50 years were found in three cases with serous histopathological cases and each case with mucinous and endometrioid subclassification types. Mixed germ cell tumors were seen in patients with ages younger than 31 years. In the 31-40 year age group, the clear cell, endometrioid, and serous subclassifications each had one case. Furthermore, the age group of 51-60 years was dominated by serous epithelial subtype cells, followed by the age group of 60 years dominated by serous cells in five cases, and mucinous in one case. It can be concluded that serous subclassification was mainly found in all age groups. The serous subtype was also the subclassification with the most patients.

Based on the research carried out by Yang et al. [9] on ovarian cancer risk factors by histological subtypes in the NIH-AARP Diet and Health Study, his findings revealed that from 849 ovarian epithelial cases, 451 (53\%) were serous cells, 78 (9\%) were endometrioid, 27 (3\%) were clear cell, and 255 (30\%) were other malignancy types. Generally, ovarian malignancy cases are based on serous cells with a mean age of about 62.5 years, mucinous at 63.5 years, and younger mean age in endometrioid and clear cells. Thus, it supports the statement in this research that those ages over 60 years were dominated by malignancies from serous epithelial cells, followed by mucinous cells. Furthermore, it is directly proportional to Dhitayoni \& Budiana [6] and Budiana et al. [7] studies, where the serous subtype dominated in cases over 30 years of age.

However, this study does not support Machida et al. [10] statement on the trends and characteristics of epithelial ovarian cancer in Japan between 2002-2015. The JSGO-JSOG joint study explained that the predominant clear cell carcinoma and endometrioid carcinoma were found to increase exponentially from 2002 to 2015 (from $32.9 \%$ to $40.3 \%$ in clear cells, $\mathrm{P}<$ 0.001 , and $23.8 \%$ to $27.2 \%$ for endometrioid, $P<0.001$ ). It is related to three socioenvironmental factors in Japan: (i) changes in the menarche and menopause age in Japan, (ii) changes in diet, marital status, and a decrease in oral contraceptives and smoking habits, (iii) a significant decrease in birth rates. These factors increase ovulation and menstruation rates in lifespan and prolong the duration of menstruation-related to the incidence and risk of endometriosis known as endometrioid precursors and clear cell carcinoma. 
The tendency to be obese or overweight increases the risk of postmenopausal breast and endometrial malignancies. However, the relationship between ovarian malignancy and obesity is still unknown. It is primarily due to individual studies not being robust to detect effects or consider the growth of the indicated histological subtypes. Based on existing theories, the relationship between obesity and hormonal changes can increase ovarian malignancy levels, where obesity causes estrogen levels in the body to increase. Furthermore, some fats produced can cause estrogen levels to rise in the form of estriol or estradiol. The changing mechanism of cholesterol is explained by hormone biosynthesis, in which every steroid hormone, including estrogen, is made from cholesterol [7].

This study found that about $44.8 \%$ of patients were diagnosed with obesity (BMI $>25 \mathrm{~kg} / \mathrm{m} 2$ ), followed by overweight (BMI $22.9-25 \mathrm{~kg} / \mathrm{m} 2$ ) around $34.5 \%$ and only $13.8 \%$ of patients with normal BMI $(18.5-22.9 \mathrm{~kg} / \mathrm{m} 2)$. It is related to Fachlevy et al. [11] statements about the risk factors for ovarian cancer at RSUP Wahidin Sudirohusodo Makassar that the bivariate analysis results using the Odds Ratio (OR) test obtained OR $=2.036$, the lower limit $(L L)=1.086$, and the upper limit $(U L)$ $=3.818$ so that respondents with $\mathrm{BMI}>30 \mathrm{~kg} / \mathrm{m} 2$ had a risk of 2.036 times greater than women with a body mass index less than $30 \mathrm{~kg} / \mathrm{m} 2$. In addition, based on the 2014 American Cancer Society Research in Ovarian Cancer report sorting, three studies on the BMI role on ovarian cancer revealed a significant and positive relationship, while nine studies mentioned no relationship between BMI and ovarian cancer [8]. Research from Momenimovahed et al. [3] directly supports this, suggesting that obesity lowers the risk of ovarian cancer survival (HR = 3.40 [1.16-9.99]) and increases the risk of death. It is associated with central adiposity, which increases the conversion of androgen in peripheral tissues.

In parity, the release of the ovum from the ovarium causes the release of estrogen production as the ovarian epithelium proliferates. Several hypotheses explain high parity as a protective factor against ovarian cancer. One of the supporting theories is incessant ovulation, mentioning that ovarian epithelial damage occurs over time when ovulation occurs. This repairing process needs time, and if this epithelial damage happens over time, especially before any previous healing is complete, or in other words, an inadequate intermission, it can lead to transformation into neoplastic cells. This theory explains why women with parity have $2 x$ less risk of suffering ovarian cancer [12].

This research reinforces the theory that $44.8 \%$ of nulliparous patients had ovarian cancer, and patients with two parity were diagnosed with ovarian cancer. This research is also adjuct by several studies that have suggested that pregnancy has a protective effect against ovarian cancer, where the risk of malignancy decreases exponentially in parous women $(P<0.001)$ and even abortions $(P<0.05)$, and this risk decreases with more parity they have $(P<0.001)$ [11]. Case-control performed by Momenimovahed et al. showed that each term pregnancy or non-mucinous tumor was 0.76 [0.69-0.85] and 1.03 [0.88-1.21] for mucinous tumors, respectively. Another research has also demonstrated that parity is associated with a consistent decrease in the relative risk of ovarian cancer, epithelial cancer, stromal cancer, and germ cell malignancies [3]. In pregnancy, there might be a delay in the ovulation process and an increase in progesterone hormone, which has a protective effect against ovarian cancer and ablution against ovarian malignancy cells [7].

From this research, it is known that there was no history of contraceptive use in every patient with ovarian cancer. It is also known that hormonal contraceptives had a protective effect on ovarian cancer by preventing a repeated ovulation process [5]. It is related to the Center for Disease Control theory, where there is a $40 \%$ decrease in the risk of ovarian cancer in women aged 20-54 years who use the contraceptive pill, with a relative risk of 0.6 . This research also reported that contraceptive pills for more than one year decreased the risk to $11 \%$ and the five-year risk by $50 \%$. This risk is proportionally reduced with the duration of use [12].

This research supports Salehi et al. [13] statement about risk factors for ovarian cancer, namely the hormonal factor approach, where women who have never used oral contraceptives will increase the risk of developing ovarian cancer. However, oral contraceptives decrease the risk of ovarian cancer by up to $40-50 \%$ compared to not using them. It was also stated that a decreased risk of ovarian cancer with oral contraceptives occurred for ten years after release. Research from Soegaard et al. [14] also mentioned a significant reduction in the risk of ovarian cancer and occurs on every histological type separately.

Almost all patients diagnosed with ovarian cancer experienced menarche at the age of 12 years, with a prevalence of $41.4 \%$, followed by 11 years at $31.0 \%$. Based on the literature, early menarche has a higher risk of ovarian cancer, ranging from a woman exposed to the estrogen hormone. It is because exposure to estrogen in a large quantity and time can activate cancer cells in the body [5]. It is exponentially proportional to Yanti and Sulistianingsih [5], who mentioned a relationship between menarche and ovarian cancer ( $P$ $=0.007)$, where $58.3 \%$ of all patients experienced menarche before 12 years. Several studies also mention menarche age on the risk of ovarian cancer, where menarche at the age of 16 instead was not absent significantly reduces the risk of ovarian cancer. It justifies the theory from Su, where there is a risk of ovarian cancer in women with menarche before 12, women 
with older menarche have low estradiol levels, need a long span for the ovulatory cycle to occur after menarche, and are relatively deficient in progesterone for several years. [15] Progestins will intensify apoptosis of the ovarian epithelium so that women with older menarche experience reduced stimulation of the ovarian epithelium by estrogen from the loss of apoptosis effect of progesterone, which eventually increases genetically damaged cells. [15] Although several studies state there is no relation between menarche or menopause and the risk of ovarian cancer, according to Momenimovahed et al. [3] research, there might be a bias in menarche's determination in this study or the previous studies with subjective values.

Based on this study, the researchers found that more than $60 \%$ of patients were diagnosed with end-stage (stadium III) ovarian cancer. Patients with IIIC ovarian cancer were the highest at $42.3 \%$, followed by IB at $17.24 \%$, indicating that mucinous and serous subtype tumors dominated patients with stadium IB. Patients diagnosed with IC were dominated with serous and endometrioid subtypes. Hence, one patient with serous, mucinous, and mixed germ cell tumors, respectively, was diagnosed with stadium IIB. However, only serous subtypes were found from patients with stadium IIIA and IIIB ovarian cancer. Also, stadium IIIC was dominated by serous and was followed by the endometrioid subtype. Thus, serous subtype tumors were found at all stages of ovarian cancer, coherent with Dhitayoni and Budiana research, which stated that serous and endometrioid were dominant in patients with stadium III and IV [6,7]. It also reinforces Chen et al. [16] who stated that serous and primarily endometrioid was seen only in patients with end-stage with more malignant and rapid characteristics. This research also predominantly found mucinous cell subtypes at an early stage, in line with Machida et al. [10] where there has been a trend of escalation of mucinous carcinoma cases in malignancy to the stadium I in the US cohort (from $15.0 \%$ into $24.8 \%, P=0.01$ ) and its theory which explains that mucinous and clear cell subtypes are one of the malignancy subtypes with slower and benign tumors. The statement by Machida et al. [10] also explained that in women from early into the late stadium, serous epithelial malignancies escalated significantly from 2002 to 2015 from Japan and US cohort (all P < 0.05), where this research demonstrated that serous epithelial malignancies remain the subtype that can be found early to the late stadium.

\section{CONCLUSIONS}

Ovarian cancer was dominantly diagnosed at the age of $51-60$ years (34.5\%). However, based on the histological characteristics, it was predominantly serous as the tumor subtype of surface epithelial-stromal tumors (65.5\%). Furthermore, concerning the stadium, ovarian cancer was mainly found in patients with stadium IIIC (42.3\%). The three factors above are relevant to theories and other studies that serous is most commonly found in the late stages and elderly, where the malignancies overgrow and move far. Moreover, the body mass index characteristic dominantly was found to be categorized as obese. Meanwhile, based on the reproductive history of menarche at the age of 12 years, mostly was noticed in inpatients with ovarian cancer. Also, it is known that nulliparous were dominantly found in ovarian cases with no history of using oral contraception nor injection.

\section{DECLARATIONS}

\section{Competing of Interest}

The authors declare no competing interest in this study.

\section{Ethical Approval}

All data is based on medical record data, ethical clearance given at ethical committee of health research Rumah Sakit Daerah Mangusada Badung mention this research is valid in ethical aspect No. 800/6044/ RSDM/2020.

\section{Funding}

The current study does not receive any specific grant from the government or any private sector.

\section{Acknowledgment}

Not applicable.

\section{REFERENCES}

1. Jelovac D, Armstrong DK. Recent progress in the diagnosis and treatment of ovarian cancer. CA Cancer J Clin. 2011;61(3):183-203.

2. Meinhold-Heerlein I, Fotopoulou C, Harter P, et al. The new WHO classification of ovarian, fallopian tube, and primary peritoneal cancer and its clinical implications. Arch Gynecol Obstet. 2016;293(4):695700.

3. Momenimovahed Z, Tiznobaik A, Taheri S, Salehiniya $H$. Ovarian cancer in the world: epidemiology and risk factors. Int J Womens Health. 2019;11:287-99.

4. Prawirohardjo S. IImu Kandungan. Jakarta: Yayasan Bina Pustaka Sarwono Prawirohardjo. 2014;7:405-406.

5. Yanti DAM, Sulistianingsih A. Determinant factors of ovarium cancer in Abdoel Moelok Hospital Lampung in 2015. Jurnal Keperawatan. 2016;7(2):79-87.

6. Dhitayoni IA, Budiana ING. Profil pasien kanker ovarium di Rumah Sakit Umum Sanglah Denpasar - Bali Periode Juli 2013-Juni 2014. E-Jurnal Medika. 2017;6(3):1-9. 
7. Budiana ING, Angelina M, Pemayun TGA. Ovarian cancer: Pathogenesis and current recommendations for prophylactic surgery. J Turk Ger Gynecol Assoc. 2019. 26;20(1):47-54.

8. American Cancer Society. Cancer Facts and Figures 2018 [internet]. Atalanta: American Cancer Society; [cited 2021 July 13]. Available from: https://www. cancer.org/content/dam/cancer-org/research/ cancer-facts-andstatistics/annual-cancer-facts-andfigures/2018/cancer-facts-and-figures-2018.pdf.

9. Yang HP, Trabert B, Murphy MA, Sherman ME, Sampson JN, Brinton LA, Hartge P, Hollenbeck A, Park $Y$, Wentzensen $N$. Ovarian cancer risk factors by histologic subtypes in the NIH-AARP Diet and Health Study. Int J Cancer. 2012;131(4):938-48

10. Machida H, Matsuo K, Yamagami W, et al. Trends and characteristics of epithelial ovarian cancer in Japan between 2002 and 2015: A JSGO-JSOG joint study. Gynecol Oncol. 2019 Jun;153(3):589-96.

11. Fachlevy AF, Abdullah Z, Russeng SS. Ovarian cancer risk factor on Wahidin Sudirohusodo Hospital Makassar. Thesis. Universitas Hassanudin Makassar; 2014
12. Su D, Pasalich M, Lee AH, Binns CW. Ovarian cancer risk is reduced by prolonged lactation: a case-control study in southern China. Am J Clin Nutr. 2013;97(2):354-9.

13. Salehi F, Dunfield L, Phillips KP, et al. Risk factors for ovarian cancer: an overview with emphasis on hormonal factors. J Toxicol Environ Health B Crit Rev. 2008;11(3-4):301-21.

14. Soegaard $M$, Jensen A, Høgdall E, Christensen L, Høgdall C, Blaakaer J, Kjaer SK. Different risk factor profiles for mucinous and nonmucinous ovarian cancer: results from the Danish MALOVA study. Cancer Epidemiol Biomarkers Prev. 2007;16(6):11606.

15. Titus-Ernstoff L, Perez K, Cramer DW, et al. Menstrual and reproductive factors in relation to ovarian cancer risk. Br J Cancer. 2001;84(5):714-21.

16. Chen T, Jansen L, Gondos A, et al; GEKID Cancer Survival Working Group. Survival of ovarian cancer patients in Germany in the early 21st century: a period analysis by age, histology, laterality, and stage. Eur J Cancer Prev. 2013;22(1):59-67. 